\title{
Exploring types of telecommuters: A latent class analysis approach
}

\section{Arne Vanderstukken, Irina Nikolova, Jeroen P. de Jong \& Monique Ramioul}

To cite this article: Arne Vanderstukken, Irina Nikolova, Jeroen P. de Jong \& Monique Ramioul (2021): Exploring types of telecommuters: A latent class analysis approach, European Journal of Work and Organizational Psychology, DOI: 10.1080/1359432X.2021.1952989

To link to this article: https://doi.org/10.1080/1359432X.2021.1952989

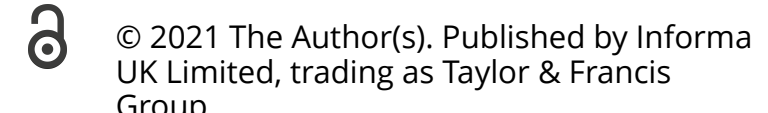
Group.

进 Published online: 15 Jul 2021.

Submit your article to this journal $\sqsubset$

Џ Article views: 139

Q View related articles $\square$

View Crossmark data ¿ 


\title{
Exploring types of telecommuters: A latent class analysis approach
}

\author{
Arne Vanderstukken ${ }^{a}$, Irina Nikolova $\mathbb{B D}^{\mathrm{b}}$, Jeroen P. de Jong ${ }^{\mathrm{c}}$ and Monique Ramioul ${ }^{\mathrm{d}}$ \\ ${ }^{a}$ Faculty of Management, Open University of the Netherlands, Heerlen, Netherlands; ${ }^{b}$ Department of Leadership and Organzational Behavior, BI \\ Norwegian Business School, Oslo, Norway; 'Faculty of Management, Radboud University Nijmegen, Nijmegen, Netherlands; dHIVA - Research \\ Institute for Work and Society, KU Leuven, Leuven, Belgium
}

\begin{abstract}
Despite initial evidence on employees' motives for telecommuting, studies so far never investigated if and how distinct telecommuting motives might co-occur. In the current study $\left(N_{\text {wave } 1}=1297\right.$ employees; $N_{\text {wave } 2}=564$ employees), we use Latent Class Analysis and identify three classes reflecting three specific combinations of telecommuting motives: the job requirement class (telecommuting because one has to), the efficiency class (telecommuting to cope with deadlines and pressure) and the work-life balance class (telecommuting to have a healthy balance between work and family/leisure). Our analyses show that employees belonging to the same class also tend to share a certain context (in terms of job characteristics such as speed of work and autonomy). Furthermore, the telecommuting motive classes predicted outcomes six months later: Whereas we found no significant associations between the job requirement class and the study outcomes, employees in the efficiency class reported more vigour and less emotional exhaustion, and employees in the work-life balance class reported more vigour, less emotional exhaustion and more job satisfaction. Implications for theory and practice are discussed.
\end{abstract}

ARTICLE HISTORY

Received 1 July 2020

Accepted 5 July 2021

\section{KEYWORDS}

Telecommuting; motives; latent classes; wellbeing

\section{Introduction}

As advanced information and communication technologies (ICTs) increasingly find their way into the workplace, telecommuting has become ubiquitous in today's organizations (Martins et al., 2004; Welz \& Wolf, 2010). The telecommuting trend has considerably impacted our physical and social work environments, with at least some of the work being done in places other than the traditional office and at least some of the interactions with co-workers taking place via email, instant messaging or videoconferencing (Gajendran \& Harrison, 2007). This impact became even more pronounced with the recent outbreak of the COVID-19 pandemic, whereby telecommuting was broadly imposed on employees as one of the restrictive measures aimed at limiting the spread of the pandemic (Gostin et al., 2020). Because for many employees telecommuting is no longer a matter of choice, more than ever practitioners and policy makers seek empirical evidence to guide their decisions regarding sustainable telecommuting practices that can foster employee motivation and wellbeing. The pressing need for insights into telecommuting is further emphasized by recent predictions that telecommuting will likely remain prevalent even after the pandemic has subsided (Baert et al., 2020; International Labour Office (ILO), 2021). This is because the unprecedented mass exposure to telecommuting enabled employees and employers alike to experience the benefits, making the practice more accepted (Baert et al., 2020; Lister, 2020).
The current study focuses on telecommuting motives, i.e., the reasons why one decides to telecommute, which are found to be key determinants of how one experiences telecommuting (e.g., Hartig et al., 2007). Even though the reasons for telecommuting may vary in their content ("to get more work done" and "to have a healthier work-life balance" are the most prominent ones; Allen et al., 2015), and in terms of who benefits directly from the telecommuting (i.e., to help meet one's own needs, or to meet the requirements of the work), it appears that those who telecommute voluntarily because it benefits their work experience and provides the most advantages in terms of wellbeing (e.g., Peters et al., 2008; Venkatesh \& Johnson, 2002). However, to date, it is not clear how telecommuting motives tend to co-occur. Authors that factor in employee telecommuting motives do so by using a variable-centred perspective (e.g., Delanoeije \& Verbruggen, 2019; Hartig et al., 2007; Mokhtarian \& Salomon, 1994). Hence, they assume that each telecommuting motive is adopted independently from other motives (i.e., having motive $A$ does not influence the likelihood of also adopting motive B) and that each motive has independent cause-effect relationships with work-related outcomes (i.e., motive $A$ leads to outcome $C$, regardless of other motives; Laursen \& Hoff, 2006). It is possible, however, that telecommuting motives only (or mostly) exist as part of one or more fixed combinations of telecommuting motives (which would invalidate the assumption of independent adoption). If so, workrelated outcomes are influenced by these combinations of 
telecommuting motives rather than single motives (which would invalidate the assumption of independent effects).

The current study strives to complement the aforementioned research by taking a person-centred perspective. Such a perspective enables a data-driven exploration of how characteristics tend to naturally co-occur within a population, i.e., of which classes (i.e., sets, combinations) of telecommuting motives can be adopted by an individual. We then propose jobrelated correlates of the classes of telecommuting motives, as well as effects of these classes on attitudinal and energetic outcomes (going beyond independent effects of single telecommuting motives).

The contributions of this paper are fourfold. First, we add to the literature by using a combination of the person-centred perspective (identifying classes of telecommuting motives) and the variable-centred perspective (identifying correlates and outcomes of these classes) on telecommuting motives, hereby accounting for the drawbacks related to the approach centred around variables alone that has been predominant thus far. A person-centred perspective has already shed new light onto several issues within the work psychology domain such as employability (Kirves et al., 2014), work-related wellbeing (Mäkikangas et al., 2014), work motivation (Van den Broeck et al., 2013) and motivation for volunteering (Geiser et al., 2014). Second, because our study includes repeated measures (two measures six months apart), we can test how stable these classes are over time, i.e., how sets of telecommuting motives change over the course of six months. Third, we investigate the contexts in which each of the telecommuting motive classes tend to occur by testing context-related correlates. In this, we include the traditional correlates used in person-centred studies such as age and gender (e.g., Bagley \& Mokhtarian, 1997). We also include several job characteristics (i.e., speed of work, lack of clarity, task problems, task variety, autonomy and job security) as antecedents. We selected these job characteristics because they are indicators of the level of complexity of the job, and person-centred studies have linked job complexity to certain isolated telecommuting motives (Mokhtarian et al., 1998). Moreover, given that these job characteristics are particularly relevant in predicting work motivation (Fernet et al., 2012), we also expect them as antecedents of employee telecommuting motives. Finally, following the logic that one's motive for a behaviour influences one's reaction to the successful completion of that behaviour, we subsequently use these classes to explain why some employees enjoy positive attitudinal and well-being consequences because of telecommuting, while others experience no or even negative consequences. Although some work has already been done on the influence of isolated telecommuting motives in this regard (e.g., Delanoeije \& Verbruggen, 2019; Hartig et al., 2007; Mokhtarian \& Salomon, 1994), the role of motive classes remains unclear.

\section{Theoretical framework and hypotheses}

Telecommuting (also referred to as telework, remote work, distributed work, and flexible work, among others; Allen et al., 2015) is usually defined as "an alternative work arrangement in which employees perform tasks elsewhere that are normally done in a primary or central workplace, for at least some portion of their work schedule, using electronic media to interact with others inside and outside the organization" (Gajendran \& Harrison, 2007, p. 1525). In general, the literature is quite positive regarding the influence of telecommuting on employees' work experience (see the meta-analysis by Gajendran \& Harrison, 2007 and the systematic review by; Charalampous et al., 2019). Specifically, employees who telecommute report slightly higher levels of autonomy, job satisfaction and performance than their non-telecommuting colleagues, and slightly lower levels of work-family conflict and role stress (e.g., Coenen \& Kok, 2014). Moreover, thanks to improvements in digital communication applications, they experience no detrimental effects on their relationships with colleagues (as long as telecommuting does not exceed the limit of three to four days a week; Hickman \& Robison, 2020).

Although employees in general are eager to telecommute, their attitudes and wellbeing likely depend on the reasons why they choose to telecommute. Indeed, motivation theories state that peoples' motives or drives for engaging in a certain behaviour (such as working remotely) are key for understanding their reactions during and after that behaviour (Deci \& Ryan, 2000; Dweck, 1986). In other words, even when two individuals engage in the exact same behaviour, they might do so for different reasons and therefore experience different consequences (Dweck, 1986). For example, when Steven attends college because he wants to gain knowledge (i.e., a learning reason) and Susan attends college because she wants to prove to others that she is intelligent (i.e., a performance reason), Steven is more likely to be truly satisfied about his achievements (Dweck, 1986). In this sense, telecommuting may affect people's attitudes and wellbeing differently depending on the specific reason(s) why they telecommute.

\section{Motives reported by telecommuters}

In the literature, telecommuters list many different reasons for telecommuting, yet the most prevalent can be captured in three categories: telecommuting to reach work-related goals, telecommuting to achieve a healthier work-life balance, and involuntary telecommuting (Allen et al., 2015; Venkatesh \& Johnson, 2002). Involuntary telecommuting (i.e., telecommuting because the job or the management requires it) is usually the result of employers introducing telecommuting for practical reasons, that is, when they believe that the advantages of remote working outweigh the disadvantages (Lapierre et al., 2016; Robèrt \& Börjesson, 2006). For instance, employers may introduce telecommuting to reduce a range of expenses by lowering overhead and accommodation costs (as fewer desks are needed on-site; Lapierre et al., 2016; Robèrt \& Börjesson, 2006). Also, some companies may introduce telecommuting in the hope that it will decrease absenteeism (arguably, telecommuting requires less effort compared with on-site work; Jackson \& van der Wielen, 1998). Given that many employers find these benefits very attractive, an increasing portion of the companies where distributed working is possible, are introducing telecommuting (Lapierre et al., 2016). However, not all employees are ready to follow this trend as some do not have good working conditions at home or simply prefer to have daily 
contact with the people in their social environment at work (Peters et al., 2004). These employees are then sometimes forced to telecommute (one or more days a week; Harris, 2003; Jemine et al., 2020; Kaduk et al., 2019; Lapierre et al., 2016). The drawbacks of involuntary telecommuting became even more apperent in the past year when due to the COVID-19 pandemic a large part of the working population around the globe was forced to work from home (Afonso et al., 2021; Como et al., 2021).

Acknowledging that some of the individuals who telecommute do not do this by choice, we expect that a portion of the telecommuters included in this study will not report any own motivation but will be telecommuting because they have to. Whereas companies might benefit from having their workforce telecommuting, this involuntary situation might have negative consequences for employees (Kaduk et al., 2019). Bartholomew et al. (2011) argue that this may be due to some of the individual's basic psychological needs might not be met or might even be thwarted. For instance, the need for autonomy in choosing and controlling one's own physical work environment, and the need for relatedness in meeting with colleagues in person, might be frustrated, indicating that involuntary telecommuting might be associated with less positive perceptions of the work characteristics and with more negative work outcomes (Bartholomew et al., 2011).

Related to the involuntary telecommuting, we need to acknowledge that even though they might be only a minority, some employees might be working involuntarily from home, not because their company requires them to, but because their health does not allow them to travel to work i.e., to overcome boundaries caused by one's health (Baruch, 2000). Indeed, some physical and psychological conditions make it temporarily or permanently impossible for people to travel to work or to work in a non-customized working environment. Telecommuting may then be the only way to work at all (Linden, 2014). Even though this category of telecommuters might be considerably underrepresented in our sample, we recognize that it exists and needs to be accounted for when discussing involuntary motives for telecommuting.

Although some employees might be forced by their company or their health to telecommute, the majority of teleworkers do so by their own choice, most notably because they want to reach work-related goals or increase their efficiency (Allen et al., 2015), by increasing their own productivity, or alternatively, by dealing more effectively with their work demands (Baruch, 2000; Salomon \& Ben-Akiva, 1983; Shockley \& Allen, 2012; Wicks, 2002). People with this drive choose to work outside the office because they expect to have better focus at home (i.e., far away from the interruptions and distractions of the office; Pyöriä, 2011), as well as a more flexible schedule (i.e., adjusting the length of one's working day to the amount of work and reducing time pressures by making good use of spare moments; Van Sell \& Jacobs, 1994; Vartiainen et al., 2007), both aimed to help them achieve greater efficiency. Prior studies indicate that up to two thirds of telecommuters choose to telecommute as means to optimize their performance and to reach their work-related goals, i.e., to become more efficient (Peters et al., 2004; Shockley \& Allen, 2012; Sullivan \& Lewis, 2001). Interestingly, managers and professionals (Mokhtarian et al., 1998) and individuals who prefer a clear segmentation between work and leisure (Shockley \& Allen, 2012) are more strongly drawn to this motive than other employees. These are typically individuals who place high value on their autonomy and may view telecommuting in function of satisfying their need for autonomy, which might be instrumental in attaining their work goals (Baruch, 2000; Meyers \& Hearn, 2001; Peters et al., 2013).

A second frequently mentioned volutary motive is the drive to achieve or maintain a healthy work-life balance (Baruch, 2000; Salomon \& Ben-Akiva, 1983; Shockley \& Allen, 2012). An important reason why employees find the idea of telecommuting so appealing is because remote work saves employees the inconveniences of the commute. Commuting is viewed by many as a daily hurdle because it is time-consuming and often involves stress with traffic or overcrowded public transport spaces (Baruch, 2000; Mokhtarian \& Salomon, 1994). Studies indicate that people who telecommute normally have longer commutes compared to people who go to work from the office (e.g., Baruch \& Nicholson, 1997). Not having to travel to work, in turn, creates the expectation that telecommuters have more time and opportunities to engage in non-work activities, such as spending time with the family, pursuing a hobby or running errands (Baruch, 2000). Whether these expectations are warranted, however, remains unclear, as some studies indicate that telecommuting potentially blurs the lines between work and non-work, actually resulting in fewer hours to spend on nonwork activities (Felstead \& Henseke, 2017; Mellner et al., 2014; Peters et al., 2008). Despite these findings, telecommuters persist in citing the motive for a healthy work-life balance when asked about their motives (albeit less frequently than the workrelated motive; Shockley \& Allen, 2012; Sullivan \& Lewis, 2001). The motive is particularly appealing to telecommuters living with a partner and telecommuters taking care of young children (Mokhtarian et al., 1998; Shockley \& Allen, 2012).

Summarizing the presented above review of literature, studies delineate two main categories of telecommuting involuntary and voluntary. Motives that are involuntary typically refer to either employees being forced to telecommute by their company policy, or because their health requires them to. Voluntary motives, on the other hand, could be grouped as "focused on work-related goals" or "focused on work-life balance" (reducing travel time or increasing non-work time). Although the aforementioned studies have provided valuable insights into telecommuting drives and motives, they all share a common methodological drawback inherent to the use of a variablecentred perspective; specifically, they make the implicit assumption that telecommuting motives are predefined and independent. The limitations associated with a variable-centred perspective can be addressed by taking a person-centred perspective, which in recent years has become increasingly popular specifically for that reason (Laursen \& Hoff, 2006; Magnusson, 2003). Using this 
approach allows for the telecommuting motives to emerge from the data, instead of being narrowly predefined by a psychometric instrument.

\section{The current study: classes of telecommuting motives}

The main goal of this study is to identify potential classes of telecommuting motives and thus to test how telecommuting motives tend to naturally co-exist within an individual. Since in earlier work researchers have always assumed that telecommuting motives are independent, indications of how motives would co-occur in classes are lacking. To provide insights into this area, we take an exploratory approach (i.e., driven by the data; McCutcheon, 1987). Nevertheless, based on the broad categories introduced earlier on (i.e., telecommuting because one has to, telecommuting to meet health-related demands, telecommuting to reach work-related goals, and telecommuting to achieve a healthy work-life balance; Allen et al., 2015; Venkatesh \& Johnson, 2002), we can make careful predictions about which classes of telecommuting motives might emerge, and whether we expect that each class will be characterized by individuals choosing one single motive, or whether classes can incorporate multiple motives.

We therefore hypothesize:

Hypothesis 1: Telecommuting motives will cluster around distinguishable classes, including but not limited to classes related to reaching work-related goals (1a), achieving a healthy work-life balance (1b), being forced by company policy (1c), and being forced by one's health (1d).

\section{Determinants of telecommuting motive classes}

If telecommuting motives tend to co-occur in several distinct classes, then correlates of telecommuting motives are in reality correlates of these classes, rather than of individual motives. Therefore, we also aim to explore if telecommuting motive classes have distinct correlates. To test for this, we complement the person-centred approach of identifying classes, with a variable-centred approach, and we explore several correlates in relation to the already identified classes.

Based on earlier variable-centred research (Mokhtarian et al., 1998), we included age, gender and level of education as potential correlates. For instance, prior studies evidenced that women, low-skilled workers and those with young children at home were more likely to mention family and stress reduction as motives for telecommuting (compared with men, highskilled workers and those without children, respectively), whereas high-skilled workers focused on the potential gains in productivity (Mokhtarian et al., 1998). Other research proposes a curvilinear effect of age on work centrality and thus presumably on the importance of telecommuting with workrelated goals in mind: it increases until the early forties and then sharply declines (Hajdu \& Sik, 2018). Considering the limited and divergent evidence, we take an exploratory approach to the (differences in) prevalence of telecommuting motive classes in different demographic groups (for a similar approach exploring correlates of mapped concepts, see Ohly \& Schmitt, 2015):

Research question 1: To what extent are telecommuting motive classes differently associated to age, gender and/or level of education?

Whereas we acknowledge that employee drive to telecommute might be co-shaped by individual characteristics (Mokhtarian et al., 1998; Walls et al., 2007), we expect that the characteristics of the job, which play a key role for the overall individual work motivation (Bakker \& Demerouti, 2007), will considerably contribute to their motivation to telework. For this reason, we investigate the propensity of job demands (i.e., aspects of the job that require energy, such as workload and ambiguity) and job resources (i.e., aspects of the job that grant energy, such as autonomy and social support; Bakker \& Demerouti, 2007; Notelaers et al., 2007) to influence employee motivation to telecommute. Following Bakker and Demerouti (2007), employees faced with high demands seek to cope with or overcome their challenging work environment and prevent exhaustion by using resources. It is therefore likely that they will attempt to deal with the strenuous working conditions by engaging in telecommuting (as a resource that allows more flexibility and autonomy) as a way of coping and preventing further resource loss and exhaustion (Salomon \& Ben-Akiva, 1983). In a sense, telecommuting might be viewed as a form of job crafting, because it involves individual agency aimed at adapting the work context to better meet the individual's needs (Wessels et al., 2019).

Moreover, employees that have ample job resources are typically energetic and more in control of their work environment (Bakker \& Demerouti, 2007). As a result, they experience less difficulties to cope with their job demands (Demerouti et al., 2001), which presumably means that they can make use of telecommuting for reasons other than finishing work and meeting deadlines, such as extra family and leisure time.

Because of the large body or research evidence showing that job demands and resources can affect employee motivation and coping strategies, we expect that they will codetermine which telecommuting class one is likely to adopt. However, because the content of each of the classes is currently unknown, we take an exploratory stance, only expecting that there will be associations between the established telecommuting motives and the characteristics of the job:

Research question 2: To what extent are telecommuting motive classes differently associated to job demands (i.e., speed of work, lack of clarity and task problems) and/or job resources (i.e., task variety, autonomy and job security)?

\section{Outcomes of telecommuting classes}

Finally, in line with the tradition of the variable-centred approach on telecommuting (Meyers \& Hearn, 2001), we scrutinize how the different telecommuting motive classes relate to important individual wellbeing and attitudinal outcomes (i.e., vigour, emotional exhaustion and job satisfaction). Above, we formulate an exploratory research question aimed at examining meaningful differences in the way job demands and resources relate to either the involuntary motives class, or 
voluntary motives classes. Prior empirical work on outcomes of telecommuting motives shows that telecommuters who are primarily driven by the requirement to conform to company policy (a coercion motive), experience lower satisfaction and wellbeing compared to those who telecommute driven by a volitional drive (e.g., the drive for a healthy work-life balance; Avgoustaki \& Bessa, 2019; Kaduk et al., 2019; Lapierre et al., 2016; Venkatesh \& Speier, 1999, 2000). These results could be explained by Self-Determination Theory (Deci \& Ryan, 2000), which proposes that people are happiest and have the most sustainable motivation when they act without external influence and interference. In line with SDT and the empirical evidence on involuntary telecommuting (Lapierre et al., 2016), it is likely that individuals who are forced by their company (or job) to telecommute, and are therefore deprived from the opportunity to work at the office in accordance with their own preferences (Venkatesh \& Johnson, 2002), will experience negative outcomes because of their frustrated psychological need for autonomy (Van den Broeck et al., 2008). Scholars have already linked the lack of need satisfaction and need thwarting to negative attitudinal, behavioural and wellbeing outcomes (Bartholomew et al., 2011; Boudrias et al., 2020; Rocchi et al., 2017). Taken together, the theoretical rationale of SDT and the empirical evidence on involuntary telecommuting (Lapierre et al., 2016) indicate that this kind of telecommuting will be associated with poor wellbeing and reduced positive attitudinal outcomes (i.e., job satisfaction). Alternatively, individuals who have the discretion to telecommute in function of their own needs might experience more positive outcomes (i.e., higher satisfaction and vigour, and lower exhaustion), because they are likely to perceive their organization as caring and invested in accommodating individual's needs and preferences; also, they might be better able to replenish their resources as voluntary telecommuting might be viewed as means towards successful job crafting (Wessels et al., 2019).

In sum, in line with the empirical evidence and the rationale discussed above it is likely that the different telecommuting motive classes will have meaningful differential relationships with employee outcomes:

Research question 3: To what extent do the different telecommuting motive classes have a different impact on employee vigor, exhaustion and job satisfaction?

Table 1. Participating organizations.

\begin{tabular}{llrr}
\hline Nickname & Start data collection & $N_{T 1}$ & $N_{T 2}$ \\
\hline BigManufac & 2016 June & 61 & 34 \\
SmallBusiness & 2016 September & 7 & 4 \\
SmallIT & 2016 September & 22 & 10 \\
BigTransport & 2017 February & 424 & 140 \\
BigHealth & 2017 February & 469 & 189 \\
BigEmp & 2017 February & 61 & 23 \\
MediumIT & 2017 May & 11 & 8 \\
MedTerritory & 2017 July & 67 & 27 \\
Biglnsurance & 2017 July & 175 & 90 \\
Missing & & & 39 \\
TOTAL & & 1297 & 564 \\
\hline
\end{tabular}


interruptions", "Because of the bad work environment in the office (e.g., noise, not enough room)", "Because of a bad relationship with a colleague (e.g., conflict, avoiding someone)", "Because it is required by the job", "To have a better work-life balance", "To reduce the time and cost of commuting", "Because of health issues (your own)" and "To have more autonomy or independence". These motives were identified by Altieri et al. (2005) by means of a field study and mostly overlap with the motives uncovered in the current literature review (e.g., "To finish work" is a work-related goal, "To have a better work-life balance" is a work-life balance goal, "Because it is required by the job" reflects being forced by company policy, and "Because of health issues (your own)" relates to being forced by one's health). This question also included an "Other" option, which was only selected by $5.17 \%$ of respondents (of which many did not propose a new motive but sought to add nuance to one of the motives they selected from the list). This indicates that the list of motives was quite complete.

\section{Sociodemographic variables}

In this study, we included three traditional correlates of telecommuting motives, i.e., gender (dichotomous variable; $0=$ "male", 1 = "female"), age (scale variable) and level of education (dichotomous variable; $0=$ "no higher education (university college or university)", 1 = "higher education (university college or university)").

\section{Job demands}

We included three variables indicating the level of demand in the job. These job demands were Speed of work (3 items; e.g., "I have to hurry to finish my work"; T1 $a=.83, \mathrm{~T} 2 \mathrm{a}=.83$ ), Lack of clarity ( 3 items; e.g., "I know exactly what others expect from me" (R); $\mathrm{T} 1 \mathrm{a}=.80, \mathrm{~T} 2 \mathrm{a}=.78$ ) and Task problems (4 items; e.g., "I get conflicting assignments"; T1 $a=.71, \mathrm{~T} 2 \mathrm{a}=.71$ ). All items were adopted from the Short Inventory to Monitor Psychological Hazards (SIMPH; Notelaers et al., 2007) and were scored on a scale ranging from 1 (= "never") to 5 (= "always").

\section{Job resources}

We also included three variables that represent the level of resources one has in the job. Task variety (4 items; e.g., "I have sufficient variety in my job"; T1 $a=.84, \mathrm{~T} 2 \mathrm{a}=.84$ ) and Autonomy (5 items; e.g., "I can decide for myself how to do my job"; T1 $a=.87, \mathrm{~T} 2 \mathrm{a}=.84$ ) were SIMPH scales (Notelaers et al., 2007) scored on a scale ranging from 1 (= "never") to 5 (= "always"). Additionally, we assessed Job security with the scale by Vander Elst et al. (2014) as an additional job resources variable (4 items; e.g., "There is a chance that I may lose my job soon" (R); $\mathrm{T} 1 \mathrm{a}=.89, \mathrm{~T} 2 \mathrm{a}=.90)$, scored on a scale ranging from 1 (= "strongly disagree") to 5 (= "strongly agree").

\section{Wellbeing and attitudinal outcomes}

We focused on three outcomes, i.e., vigour, emotional exhaustion and job satisfaction. Vigour was assessed with the UBES ( 3 items; e.g., "When I get up in the morning, I feel like going to work"; T1 $a=.85, \mathrm{~T} 2 \mathrm{a}=.87$; Schaufeli \& Bakker, 2004) on a scale ranging from 1 (= "never") to 5 (= "always"). Next, Emotional exhaustion was measured with the UBOS (5 items; e.g., "I feel burned out because of my job"; T1 $a=.89$, T2 $a=.90$; Maslach et al., 2001), again on a scale ranging from 1 (= "never") to 5 (= "always"). Finally, Job satisfaction was assessed with the MOAQJSS (3 items; e.g., "All in all I am satisfied with my job"; T1 $a=.85$, $\mathrm{T} 2 \mathrm{a}=.88$; Cammann et al., 1983), using a scale ranging from 1 (= "strongly disagree") to 5 (= "strongly agree").

\section{Factor structure of the measures}

To check the factor structure of the items of job demands (i.e., speed of work, lack of clarity and task problems), job resources (i.e., task variety, autonomy and job security) and outcomes (i.e., vigour, emotional exhaustion and job satisfaction), we ran three nested CFA models (see Table 2). Model 1 had all the items load on one general factor, Model 2 had all the items related to the independent variables load on one factor and all the items related to the dependent variables load on another factor (two factors in total: independent variable and dependent variable), and Model 3 had the items grouped like one would expect based on the scales used (nine factors in total: speed of work, lack of clarity, task problems, task variety, autonomy, job security, vigour, emotional exhaustion and job satisfaction). In relative terms, with each further specification, there is a significant decrease in the $\mathrm{Chi}^{2}$ statistic $\left(\Delta \mathrm{Chi}^{2}\right.$ Model 1 , Model $2(1)=1575 ; p<.01 ; \Delta \mathrm{Chi}^{2}$ Model 2 , Model $\left.3(35)=8558 ; p<.01\right)$, which means that the most specified model (i.e., the nine factor model with the theoretical scales) shows the best fit with the data. In absolute terms, the fit indices of the most specified model are not perfect (e.g., $T L I<.95)$, yet we believe we can proceed as CFI (a fit index insensitive to sample size), RMSEA (a fit index adjusted for parsimony) and SRMR are acceptable ( $\geq$ $.90,<.08$, and < .08, respectively; Hooper et al., 2008).

\section{Analytical strategy}

Our study aims to explore unobserved subgroups based on telecommuting motives. We use Latent Class Analysis (LCA; McCutcheon, 1987) in Mplus (L. K. Muthén \& Muthén, 2019) on our set of ten categorical (yes/no) observed motives to uncover these subgroups. We conduct this analysis on the participants that telecommuted (i.e., that worked from a location other than the office for at least some portion of their schedule and that used ICTs to communicate with colleagues; 938 participants in wave 1 and 437 participants in wave 2). The participants that did not telecommute ${ }^{1}$ (359

Table 2. Fit indices of three nested CFA models to check the factor structure of the scales.

\begin{tabular}{|c|c|c|c|c|c|c|c|c|c|c|c|}
\hline Model & Number of factors & $\mathrm{Chi}^{2}$ & $d f$ & $p$ & RMSEA & $p(R M S E A \leq .05)$ & CFI & $T L I$ & SRMR & $\Delta \mathrm{Chi}^{2}$ & $p$ \\
\hline 1 & 1: General factor & $12,054.71$ & 527 & $<.01$ & .15 & $<.01$ & .44 & .40 & .13 & & \\
\hline 2 & 2: Independent variables and dependent variables & $10,479.70$ & 526 & $<.01$ & .14 & $<.01$ & .52 & .49 & .12 & 1575 & $<.01$ \\
\hline 3 & 9: Theoretical scales & 1921.26 & 491 & $<.01$ & .05 & .03 & .93 & .92 & .05 & 8558 & $<.01$ \\
\hline
\end{tabular}


Table 3. Fit indices for LCA models Wave 1.

\begin{tabular}{lccll} 
Model & BIC & $d f$ & $V L M R$ & $L M R$ \\
\hline 1-class & 9632.38 & 1008 & NA & NA \\
2-class & 9482.20 & 999 & .173 & .176 \\
3-class & 9304.66 & 988 & .000 & .000 \\
4-class & 9306.36 & 978 & .234 & .237 \\
5-class & 9349.10 & 968 & .364 & .366 \\
\hline
\end{tabular}

Table 4. Fit indices for LCA models Wave 2.

\begin{tabular}{lccll}
\hline Model & $B I C$ & $d f$ & $V L M R$ & $L M R$ \\
\hline 1-class & 4479.78 & 1010 & NA & NA \\
2-class & 4411.56 & 999 & .021 & .022 \\
3-class & 4350.79 & 987 & .005 & .006 \\
4-class & 4381.76 & 977 & .146 & .149 \\
5-class & 4407.53 & 967 & .014 & .015 \\
\hline
\end{tabular}

Table 5. Loadings of telecommuting reasons on latent classes Wave 1.

\begin{tabular}{lrrr}
\hline Reason & Class & Class & Class \\
& 1 & 2 & 3 \\
\hline To finish work & 0.209 & 0.865 & 0.130 \\
To catch up on work & 0.051 & 0.541 & 0.049 \\
To avoid interruptions & 0.056 & 0.495 & 0.292 \\
Because of the bad work environment in the office (e.g., & 0.054 & 0.276 & 0.171 \\
$\quad$ noise, not enough room) & & & \\
Because of a bad relationship with a colleague (e.g., & 0.000 & 0.034 & 0.015 \\
$\quad$ & & & \\
$\quad$ conflict, avoiding someone) & 1.000 & 0.223 & 0.065 \\
Because it is required by the job & 0.117 & 0.566 & 0.769 \\
To have a better work-life balance & 0.112 & 0.468 & 0.726 \\
To reduce the time and cost of commuting & 0.000 & 0.058 & 0.062 \\
Because of health issues (your own) & 0.076 & 0.184 & 0.209 \\
To have more autonomy or independence & $11 \%$ & $44 \%$ & $45 \%$ \\
\% of telecommuting participants & & &
\end{tabular}

Table 6. Loadings of telecommuting reasons on latent classes Wave 2.

\begin{tabular}{lrrr}
\hline Reason & Class & Class & Class \\
& 1 & 2 & 3 \\
\hline To finish work & 0.421 & 0.849 & 0.109 \\
To catch up on work & 0.180 & 0.663 & 0.035 \\
To avoid interruptions & 0.059 & 0.532 & 0.365 \\
Because of the bad work environment in the office (e.g., & 0.000 & 0.343 & 0.180 \\
$\quad$ & & & \\
$\quad$ noise, not enough room) & 0.000 & 0.014 & 0.022 \\
Because of a bad relationship with a colleague (e.g., & & & \\
$\quad$ conflict, avoiding someone) & 0.766 & 0.206 & 0.113 \\
Because it is required by the job & 0.103 & 0.644 & 0.838 \\
To have a better work-life balance & 0.091 & 0.472 & 0.748 \\
To reduce the time and cost of commuting & 0.000 & 0.055 & 0.102 \\
Because of health issues (your own) & 0.042 & 0.175 & 0.186 \\
To have more autonomy or independence & $16 \%$ & $32 \%$ & $52 \%$ \\
\% of telecommuting participants & & & \\
\hline
\end{tabular}

participants in wave 1 and 127 participants in wave 2) are excluded from the $\mathrm{LCA}^{2}$ and are used in subsequent analyses as a control group, i.e., the no telecommuting class. We first conduct an LCA on the data of Wave 1, and aim to confirm the LCA in Wave 2. The purpose of a LCA is to categorize people into classes using the observed items and identify items that best distinguish between classes (Nylund et al., 2007). LCA starts with testing the assumption that there is only one group, and then systematically estimates models consisting of two, three, or even more different classes (Vermunt \&
Magidson, 2002). The model with the number of classes that statistically fits the data best is chosen for further analysis. For the selection of latent class models we use the Bayesian Information Criteria (BIC). We used the BIC, because it often rewards a more parsimonious model and should be selected for large item numbers and small pattern frequencies (Nylund et al., 2007). When comparing a series of models, the model with the lowest IC value is selected. We also report Vuong-LoMendell-Rubin Likelihood Ratio Test (VLMR) and the LoMendell-Rubin Adjusted Likelihood Ratio Test (LMR) to assess the improvement of the k-1 model compared to the model with k classes.

Using the latent classes of telecommuting motives, we can then proceed with testing correlates and outcomes that may be unique to each latent class, also known as auxiliary variables (Clark \& Muthén, 2009). To examine correlates, we conduct oneway ANOVAs on the continuous correlates (i.e., age, job demands and job resources) to test for differences between $\mathrm{T} 1$ latent classes, and $\mathrm{Chi}^{2}$ tests on the binary correlates (i.e., gender and level of education). These analyses are followed up by pairwise comparisons using the Bonferroni method. Finally, to scrutinize differential outcomes, we conduct multiple regression analyses, regressing T2 outcomes (i.e., vigour, emotional exhaustion and job satisfaction) onto class memberships at T1 (as dummy variables, while controlling for T1 outcomes).

\section{Results}

\section{Latent class analysis}

We hypothesized that telecommuting motives would cluster around distinguishable classes. These may be characterized by the following themes: work-related goals ( $\mathrm{H} 1 \mathrm{a})$, work-life balance $(\mathrm{H} 1 \mathrm{~b})$, forced by company policy $(\mathrm{H} 1 \mathrm{c})$ or forced by one's health $(\mathrm{H} 1 \mathrm{~d})$. Table 3 and 4 report the results of the LCA and compares the BIC, VLMR and LMR of the 1-, 2-, 3-, 4-, and 5-class models in the Wave 1 and Wave 2 data, respectively. The tables show that the 3-class model shows the lowest BIC value in both the Wave 1-dataset (9304.66) and the Wave 2-dataset (4350.79). At both measurement points, the VLMR and LMR show that the 3-class model significantly improves the fit compared to the 2-class model, and that the 4-class model does not significantly improve the fit compared to the 3-class model. On the basis of these results we can conclude that the 3 -class model fits the data best in both the Wave 1 and Wave 2-datasets.

In Table 5 and 6 we report the probabilities of answering "yes" to each item for each class of motives in Wave 1 and Wave 2. Members of class 1 are more likely compared to the other classes to telecommute because the job requires it. This is the only reported motive, which is why we label this class as "Job requirement". Since it reflects coercion, hypothesis $1 \mathrm{c}$ was supported. Members of class 2 were labelled "Efficiency" as they are highly likely to telecommute because this will benefit their productivity ("To finish work", "To catch up on work", "To avoid interruptions"), as well as moderately likely to telecommute to improve their own quality of life ("To have a better work-life balance", and "To reduce the time and cost of commuting"). These are mostly work-related goals, so the results supported hypothesis 1a (although it has to be noted that work-life balance 
is also of some concern to this class). Finally, members of class 3 agree with two particular motives; "To have a better work-life balance", and "To reduce the time and cost of commuting". These respondents appear to telecommute to achieve a better worklife balance, also by reducing the costs of commuting. We name this class "Work-life balance", which is in support of hypothesis $1 \mathrm{~b}$. We did not find a class reflecting telecommuting because of one's health nor was this motive part of one of the other classes, so hypothesis $1 \mathrm{~d}$ was not supported. As Table 5 and 6 show, the distribution of probabilities is highly similar in Wave 1 and Wave 2 , which suggests that the content and distribution across the subgroups is stable.

\section{Correlates of telecommuting motive classes}

After having established the different telecommuting motive classes, we explore how age, gender and level of education relate differently to the different telecommuting motive classes (research question 1). We scrutinized the link between these correlates and the telecommuting classes by conducting one-way ANOVAs for continuous correlates and $\mathrm{Chi}^{2}$ tests for binary correlates (as well as subsequent pairwise comparisons). The telecommuting motive classes only showed significant differences in terms of level of education (Pearson $\mathrm{Chi}^{2}(3)=27.19 ; p<.01$; see Table 7). Specifically, the no telecommuting class included significantly fewer highly educated employees compared with the job requirement class $(p<.01)$, the efficiency class $(p<.01)$ and the work-life balance class $(p<.01)$. The telecommuting motive classes did not differ in terms of age $(F(3,1213)=2.46 ; p=$ .06 ), and gender (Pearson $\mathrm{Chi}^{2}(3)=3.41 ; p=.33$ ).

Moreover, we investigate the link between contextual variables (job demands and job resources) and telecommuting motive classes using a similar approach (research question 2). The results showed that telecommuting motive classes differed in terms of speed of work, task variety, and autonomy (see Table 7). The efficiency class scored significantly higher on speed of work $(F(3,1184)=4.34 ; p=.01)$ than the work-life balance class $(p=.04)$ and the no telecommuting class $(p=.01)$, as well as significantly higher on task variety $(F(3,1170)=9.79 ; p<.01)$ than the job requirement class $(p=.01)$ and the no telecommuting class $(p<$ $.01)$. Finally, the work-life balance class scored higher on autonomy $(F(3,1170)=5.05 ; p<.01)$ than the no telecommuting class $(p<.01)$, but not the efficiency class. The telecommuting motive classes did not differ in terms of lack of clarity $(F(3,1185)=2.38 ; p=.07)$, task problems $(F$ $(3,1184)=0.25 ; p=.86)$, and job security $(F(3,1169)=0.44$; $p=.73)^{3}$

\section{Outcomes of telecommuting motives classes}

Finally, we explore if different telecommuting motive classes have different outcomes in terms of wellbeing and job satisfaction (research question 3). Multiple regression analyses (see Table 8 ) revealed that having a job requirement motives class

Table 7. Descriptive statistics of contextual and demographic variables specific for each telecommuting motive class, with mean and standard deviation for scale variables (job demands, job control and age) and proportions for binary variables (gender and education).

\begin{tabular}{|c|c|c|c|c|c|c|c|c|c|c|c|c|}
\hline & \multicolumn{3}{|c|}{ Job requirement } & \multicolumn{3}{|c|}{ Efficiency } & \multicolumn{3}{|c|}{ Work-life balance } & \multicolumn{3}{|c|}{ No telecommuting } \\
\hline & $\bar{x}$ & $S D$ & $P$ & $\bar{x}$ & $S D$ & $P$ & $\bar{x}$ & $S D$ & $P$ & $\bar{x}$ & $S D$ & $P$ \\
\hline Speed of work & 3.23 & 0.74 & & 3.30 & 0.71 & & 3.14 & 0.78 & & 3.10 & 0.81 & \\
\hline Lack of clarity & 2.48 & 0.54 & & 2.54 & 0.49 & & 2.45 & 0.49 & & 2.45 & 0.57 & \\
\hline Task problems & 2.21 & 0.74 & & 2.24 & 0.66 & & 2.20 & 0.62 & & 2.23 & 0.72 & \\
\hline Task variety & 3.67 & 0.75 & & 3.91 & 0.72 & & 3.81 & 0.70 & & 3.61 & 0.77 & \\
\hline Autonomy & 3.61 & 0.68 & & 3.67 & 0.67 & & 3.67 & 0.69 & & 3.47 & 0.79 & \\
\hline Job security & 3.92 & 0.96 & & 3.98 & 0.90 & & 3.97 & 0.85 & & 3.91 & 0.92 & \\
\hline Gender (1 = female) & & & .54 & & & .49 & & & .55 & & & .52 \\
\hline Age & 44.28 & 10.18 & & 43.44 & 10.23 & & 43.38 & 10.37 & & 45.35 & 10.89 & \\
\hline Education ( 1 = higher education) & & & .79 & & & .78 & & & .77 & & & .62 \\
\hline
\end{tabular}

Table 8. Results of regression analyses testing the influence of T1 telecommuting classes on T2 outcomes.

\begin{tabular}{|c|c|c|c|c|c|c|}
\hline & \multicolumn{2}{|c|}{ T2 Vigour } & \multicolumn{2}{|c|}{ T2 Emotional exhaustion } & \multicolumn{2}{|c|}{ T2 Job satisfaction } \\
\hline & $B$ & $S E B$ & $B$ & $S E B$ & $B$ & SE B \\
\hline Constant & $3.28^{* *}$ & 0.25 & $2.85^{* *}$ & 0.26 & $3.48^{* *}$ & 0.28 \\
\hline Job requirement dummy & 0.27 & 0.15 & -0.29 & 0.16 & 0.17 & 0.16 \\
\hline Efficiency dummy & $0.24^{*}$ & 0.12 & $-0.27^{*}$ & 0.13 & 0.20 & 0.12 \\
\hline Work-life balance dummy & $0.35^{* *}$ & 0.12 & $-0.29 *$ & 0.13 & $0.26^{*}$ & 0.12 \\
\hline Gender ( 1 = female) & -0.07 & 0.07 & 0.01 & 0.08 & 0.06 & 0.07 \\
\hline Age & -0.01 & 0.01 & 0.01 & 0.01 & -0.01 & 0.01 \\
\hline Education ( 1 = higher education) & -0.01 & 0.09 & 0.03 & 0.09 & 0.01 & 0.09 \\
\hline T1 outcome & -0.04 & 0.05 & -0.02 & 0.05 & 0.07 & 0.05 \\
\hline $\mathrm{R}^{2}$ & 0.02 & & 0.01 & & 0.02 & \\
\hline
\end{tabular}

Note $1 .{ }^{*} p<.05,{ }^{* *} p<.01$ 
Table 9. Results of binary logistic regression analyses testing the influence of T1 job demands and job control on switching to/staying with a telecommuting motive class, controlling for gender, age and education.

\begin{tabular}{|c|c|c|c|c|c|c|c|c|c|c|c|c|c|c|c|c|}
\hline & \multicolumn{4}{|c|}{ Job requirement } & \multicolumn{4}{|c|}{ Efficiency } & \multicolumn{4}{|c|}{ Work-life balance } & \multicolumn{4}{|c|}{ No telecommuting } \\
\hline & \multicolumn{2}{|c|}{ Stay with } & \multicolumn{2}{|c|}{ Switch to } & \multicolumn{2}{|c|}{ Stay with } & \multicolumn{2}{|c|}{ Switch to } & \multicolumn{2}{|c|}{ Stay with } & \multicolumn{2}{|c|}{ Switch to } & \multicolumn{2}{|c|}{ Stay with } & \multicolumn{2}{|c|}{ Switch to } \\
\hline & $B$ & SE B & $B$ & $S E B$ & $B$ & $S E B$ & $B$ & SE B & $B$ & $S E B$ & $B$ & $S E B$ & $B$ & SE B & $B$ & SE B \\
\hline Constant & NA & & $-5.71^{* *}$ & 1.63 & $-10.34^{* *}$ & 1.81 & $-3.60^{*}$ & 1.44 & -0.59 & 1.32 & 3.45 & 1.17 & -1.18 & 1.72 & -1.04 & 1.44 \\
\hline Speed of work & NA & & -0.21 & 0.31 & 0.41 & 0.32 & $0.59^{*}$ & 0.29 & -0.09 & 0.26 & -0.38 & 0.22 & 0.07 & 0.35 & -0.19 & 0.27 \\
\hline Lack of clarity & NA & & 0.81 & 0.72 & 0.75 & 0.74 & 0.11 & 0.67 & -0.53 & 0.62 & -0.06 & 0.52 & -0.38 & 0.83 & -0.09 & 0.65 \\
\hline Task problems & NA & & -0.32 & 0.41 & -0.26 & 0.42 & -0.24 & 0.39 & 0.44 & 0.35 & -0.28 & 0.30 & 0.27 & 0.48 & 0.16 & 0.37 \\
\hline Task variety & NA & & $0.52^{*}$ & 0.25 & $0.65^{*}$ & 0.26 & -0.18 & 0.21 & -0.19 & 0.19 & -0.02 & 0.17 & -0.39 & 0.25 & -0.12 & 0.21 \\
\hline Autonomy & NA & & -0.01 & 0.26 & $0.63^{*}$ & 0.28 & 0.31 & 0.23 & 0.19 & 0.21 & $-0.53^{*}$ & 0.18 & -0.17 & 0.26 & -0.06 & 0.22 \\
\hline Job security & NA & & -0.20 & 0.17 & 0.02 & 0.18 & -0.01 & 0.16 & 0.04 & 0.15 & -0.05 & 0.13 & -0.01 & 0.20 & 0.24 & 0.17 \\
\hline Gender ( $1=$ female $)$ & NA & & -0.25 & 0.28 & -0.20 & 0.28 & 0.48 & 0.27 & 0.12 & 0.25 & 0.04 & 0.21 & -0.03 & 0.33 & -0.28 & 0.26 \\
\hline Age & NA & & $0.04^{*}$ & 0.01 & 0.01 & 0.02 & -0.02 & 0.01 & -0.01 & 0.01 & $-0.03^{*}$ & 0.01 & $0.04^{*}$ & 0.02 & -0.01 & 0.01 \\
\hline Education ( $1=$ higher education) & NA & & 0.12 & 0.35 & 0.36 & 0.40 & 0.05 & 0.32 & -0.11 & 0.28 & $0.77^{*}$ & 0.27 & $-1.42^{*}$ & 0.34 & -0.22 & 0.30 \\
\hline Nagelkerke $\mathrm{R}^{2}$ & NA & & 0.06 & & 0.14 & & 0.05 & & 0.02 & & 0.09 & & 0.15 & & 0.02 & \\
\hline
\end{tabular}

Note $1 .{ }^{*} p<.05,{ }^{* *} p<.01$

Note 2 . The "stay with job requirement class" was too small $(N(1)=8)$ for the analysis.

had no significant effect on any of the study outcomes (i.e., vigour, emotional exhaustion and job satisfaction) six months later. Having an efficiency motives class, however, did significantly increase vigour and decrease emotional exhaustion. Yet, this class had no significant effect on job satisfaction. Finally, having a work-life balance motives class had a significant influence on all T2 outcome variables. Specifically, having such a class increased vigour, decreased emotional exhaustion and increased job satisfaction.

\section{Additional analyses}

In the Latent Class Analysis, we found that only $37.7 \%$ of respondents (212 of 562) were assigned to the same class at $\mathrm{T} 1$ and T2. Because a large number of participants (i.e., 62.3\%) switched from one class to another over the course of six months, and given that it has been suggested that employees adjust their telecommuting motives to suit their current work environment (Salomon \& Ben-Akiva, 1983), we conducted additional analyses to test if the demographic and contextual variables could predict a transition to a certain telecommuting motive class at T2. For this, we created binary variables which indicated the class at $\mathrm{T} 2$, as well as whether the participant switched classes or not. In other words, the new variables were "stay with job requirement class", "switch to job requirement class", "stay with efficiency class", "switch to efficiency class", "stay with work-life balance class", "switch to work-life balance class", "stay with no telecommuting", and "switch to no telecommuting", with a value of ' 1 ' meaning that the variable name is applicable. We subsequently carried out binary logistic regressions with each of the new binary variables as the dependent variable to test if the demographic and contextual variables at T1 could increase the chances of staying with or switching to each of the telecommuting motive classes (see Table 9). The results showed that employees were significantly more likely to switch to the job requirement class when they experienced higher levels of task variety and were older; would switch to the efficiency class when they experienced higher speed of work; and would switch to the work-life balance class when they experienced lower levels of autonomy and when they were at a younger age.

\section{Discussion}

In this study we used a person-centred approach to uncover how telecommuting motives tend to co-exist within an individual (i.e., which latent classes of telecommuting motives exist). Three distinct classes emerged from the data (excluding the control group that did not engage in telecommuting). First, we identified a job requirement motive class with employees who telecommute because the job requires them to telecommute. Second, we found an efficiency motive class with employees who telecommute for several reasons related to improving one's work efficiency (i.e., finishing work and, to a lesser extent, reducing travel time and achieving a work-life balance). The third class we identified was a work-life balance motive class with employees telecommuting to achieve the right balance between work and leisure/family (and, to a lesser extent, reduce travel times). Contrary to our predictions, however, we did not find a class for employees telecommuting because of their health, and the efficiency class was not exclusively characterized by work-related goals (a healthy work-life balance was also moderately likely to be mentioned). Furthermore, we linked the telecommuting motive classes to several theoretically meaningful correlates and outcomes, and established that a considerable number of employees switched from one class to another, adjusting their telecommuting motives to fit with their current job contents. These results have various theoretical and practical implications.

\section{Theoretical implications}

The current study adds to the body of literature evidencing that the outcomes of telecommuting are partly determined by the reason why the employee decided to telecommute in the first place (e.g., Avgoustaki \& Bessa, 2019; Peters et al., 2004) in three ways: (1) we show that telecommuting motives tend to be adopted as one of three delineated sets rather than as independent motives, (2) our findings indicate that research on telecommuting should focus on correlates and outcomes of classes of motives rather than on correlates and outcomes of independent motives, and (3) we provide evidence that telecommuters change (classes of) motives more frequently than 
previously thought, often as a consequence of altered work environments.

Prior (i.e., variable-centred) research typically originated from the implicit assumption that motives are adopted independently, i.e., that adopting one motive does not affect the likelihood of adopting another motive (Laursen \& Hoff, 2006; Magnusson, 2003). In other words, it was assumed that telecommuters were driven by different, unrelated and thus freely combined motives. This assumption does not align with the findings of the current study, as we show that telecommuters tend to adopt one of several delineated sets of motives rather than a single, independent motive. For instance, our results indicate that employees who adopt the efficiency motive class are highly likely to report that they telecommute to finish work, and are moderately likely to report that they telecommute to achieve other work-related goals, to maintain a healthy worklife balance and to reduce the inconvenience of travelling (i.e. a travel-related drive). Alternatively, telecommuters who adopt the work-life balance motive class are highly likely to be simultaneously driven by their desire to achieve a healthy work-life balance (i.e., adopt a healthy work-life balance drive) and (albeit somewhat less likely) adopt a travel-related drive. The job requirement motive class, however, deviated from this general trend that drives tend to "travel together", as only the drive to conform to the new company policy was underlying it (and was therefore adopted independently from other motives). Overall, our results show that telecommuting motives are unlikely to occur as independent single motives, instead, they might emerge as classes that combine multiple motives.

Notably, the efficiency motive class and the work-life balance motive class have a degree of overlap (albeit with different likelihoods) as both classes incorporate "telecommuting to maintain a healthy work-life balance" and "telecommuting to reduce travel time" as a motive. The job requirement motive class, on the other hand, showed no overlap of motives with other classes. These results might reflect the voluntary vs involuntary nature of the motives (Venkatesh \& Johnson, 2002). Because the workefficiency and the work-life balance classes incorporate voluntary motives, it seems likely that some of these motives could coexist. Individuals who are in the two voluntary classes have the freedom to choose to telecommute (or not) in order to accommodate their needs and craft towards a better work and home situation. Individuals in the coercion class, however, are deprived from such opportunity, which makes this class substantially different from the voluntary classes.

These results have additional implications for some of the drives identified within the variable-centred approach. Notably, telecommuting to reduce travel time did not only belong to the work-life balance motive class, but was also often selected together with work-related goals (as part of the efficiency motive class). We therefore propose that reducing travel time and cost is possibly a secondary goal, i.e., a means through which one can reach both efficiency and work-life goals. A second unexpected outcome is that telecommuting forced by one's health and telecommuting to satisfy the need for autonomy (a work-related goal) were altogether absent from the classes, despite being rather prevalent in prior work (Linden, 2014; Meyers \& Hearn, 2001). Many reasons may account for this absence. For example, telecommuting forced by one's health may have been rarely selected by the respondents in our study because individuals who telecommute for health reasons remain an underrepresented group in most industries (Eurostat, 2018), especially in countries characterized by a relatively good social protection system such as Belgium (the country in which the study was conducted; Eurostat, 2011), and therefore do not have sufficient representation, which is needed to form a statistically distinct class in studies such as this one. Alternatively, it is possible that employees with a disability or health problems self-selected out of our study, i.e., that the likelihood of them choosing not to participate was much higher than in other groups, because participating may be more taxing for them.

Also, enjoying more work autonomy as a reason for teleworking (i.e., "To have more autonomy or independence") was rarely selected by our participants and was not included in any of the classes. Nevertheless, some studies indicate that telecommuting to enhance one's own autonomy is particularly rewarding because it involves doing one's job in accordance with his or her beliefs (Meyers \& Hearn, 2001; O'Neill et al., 2009). The reason why autonomy did not emerge as a key drive in this study may be because employees realize that telecommuting does not always increase autonomy, especially, when supervisors try to control telecommuters by frequently checking in on them via email or telephone (Lautsch et al., 2009). Another possible explanation why autonomy did not add to one of the classes, might be related to the social policies of the country where the study was set up. The Belgian employee may already enjoy a relatively good level of autonomy at work or at home, so autonomy is not seen as an important reason to telecommute. Belgium has a strong union protection of workers that has contributed to better jobs (Vandaele, 2005). In addition, it has a law (Act of 4 August 1996) which requires companies to have the psychosocial conditions of their workplace to be evaluated by an external social auditing company; as a result, much attention has been given to some of the key job characteristics in companies and especially to autonomy.

As a second theoretical implication, our finding that multiple motives might co-exist in one of three classes suggests that research might need to focus on correlates and outcomes of classes of telecommuting motives, rather than on correlates and outcomes of individual telecommuting motives (as earlier implied by the variable-centred perspective; see e.g., Mokhtarian et al., 1998; Shockley \& Allen, 2012). Indeed, if motives are adopted as a class, sociodemographic and workplace characteristics increase the likelihood of adopting the class (Laursen \& Hoff, 2006). In other words, our findings show that certain situations prompt complex motivational reactions in telecommuters that are not captured in simple antecedentmotive relationships. For instance, we were able to establish that the efficiency motive class is adopted mostly by people working in jobs with a high workload, a high variety in tasks and high levels of autonomy. These results align with the research of Mokhtarian et al. (1998), who showed that the workrelated drive is typically selected by managers and professionals as the main reason to telecommute, yet we extend previous knowledge by showing that this work-related drive in reality encompasses more than one underlying motive, including a drive for a healthy work-life balance and a travel- 
related drive. Furthermore, we extend earlier work by highlighting that telecommuters that have variety and autonomy in their jobs could adopt the work-life balance motive class, an interplay between the drive for a healthy work-life balance and a (secondary) travel-related drive. Interestingly, this class was not typical for certain genders or age groups such as parents of young children, as one might expect based on prior research (Mokhtarian et al., 1998; Shockley \& Allen, 2012). It is, however, in line with the proposition that all telecommuters might strive towards a healthy work-life balance and value their time for a variety of non-work activities (e.g., family, hobbies and friends; Keeney et al., 2013). The job requirement class is an exception as it contains only one motive; it is typically adopted by employees who experience relatively low levels of task variety.

Another consequence of the result that telecommuters adopt one of the three delineated classes of motives rather than a single motive, is that it is more realistic and useful to scrutinize the outcomes of motive classes as a unit. By doing so, we found that belonging to the efficiency class increases vigour and reduces emotional exhaustion. These results are in line with earlier findings that the work-related drive increases productivity and reduces stress (Parasuraman \& Greenhaus, 2002; Wessels et al., 2019), yet they add by showing that the workrelated drive cannot be disentangled from the other drives in the efficiency class. Moreover, of all three classes identified in this study, the work-life balance motive class was the most beneficial for employee wellbeing and attitudes, because this class was associated with a decrease in emotional exhaustion, and an increase in vigour and job satisfaction. This seems at odds with prior research showing mixed outcomes of the drive for a healthy work-life balance (Felstead \& Henseke, 2017; Mellner et al., 2014; Peters et al., 2008), which could be because our sample consisted of people who already had some experience with telecommuting (i.e., respondents in the work-life balance motive class had on average four years of telecommuting experience) and therefore knew how to control the boundary-defying aspects of the practice (Mellner et al., 2014). Additionally, we show that the effects of the drive for a healthy work-life balance cannot be disentangled from the other drive in the class (i.e., the travel-related drive). Finally, the results show that telecommuters did not experience any changes in wellbeing by being motivated by the job requirement class (i.e., no increase in job satisfaction and engagement, as well as no decline in emotional exhaustion). This is mostly in line with the outcomes reported in variable-centred studies on forced telecommuting (although these are occasionally more severe, like a much lower job satisfaction; Avgoustaki \& Bessa, 2019; Venkatesh \& Johnson, 2002).

As a third and final theoretical implication, our results suggest that telecommuters switch motives (in this case: motive classes) more frequently than assumed by earlier contributions, as they mostly took into consideration the rather stable sociodemographic variables (e.g., gender and age) as correlates of telecommuting motives (Mokhtarian et al., 1998; Mokhtarian \& Salomon, 1997). Although some scholars indicated that telecommuting motives may be more susceptible to change because people might adapt their telecommuting motives following potential changes in their work environment (Salomon
\& Ben-Akiva, 1983), until now empirical evidence for this claim was lacking. The current study shows that telecommuting motives are indeed malleable, as it demonstrates that over time employees tend to change from one telecommuting motive class to another (i.e., about $60 \%$ changed classes between T1 and T2). Our findings indicate that this is because motives are not only formed by the individual's stable traits such as sociodemographic characteristics, but they also depend on the more dynamic job characteristics to which they are exposed (e.g., speed of work, task variety and autonomy). Therefore, as evidenced by the additional analyses (Table 9), to maintain an optimal person-job fit, employees seem to adjust their telecommuting motives in line with the changes in the characteristics of their jobs (e.g., adopting a work-life balance class when business is slow and changing to the efficiency class when approaching deadlines). One could consider telecommuting as a strategy to cope with demands at work. In a broader sense, telecommuting could therefore serve as a powerful tool for job crafting, i.e., a means for employees to shape their own work environment and regain control over their job (Wrzesniewski \& Dutton, 2001). Moreover, it is possible that employees adjust their motives to cope with other, nonwork events as well. For example, when a family member has fallen ill, employees could switch to the work-life balance class. It is also possible that, as telecommuters are confronted with extreme and unprecedented circumstances (such as the recent outbreak of the COVID-19 pandemic), new classes of telecommuting motives emerge that fit the new situation. Consequently, research is needed to monitor telecommuters' reactions to such events.

\section{Practical implications}

Our findings suggest that organizations may benefit of (re-) designing jobs in a way that provides employees with ample task variety, decision latitude, and sufficiently activating pace of work, because these job characteristics were linked to at least one of the two wellbeing promoting classes - the efficiency and the work-life balance motive class. Our call inviting organizations to increase the task variety and decision latitude of their employees resonates with prior studies suggesting that job re-design interventions aimed at boosting job resources can be valuable for both employees and organizations (Nielsen et al., 2017; Onwezen et al., 2014). Because job re-designing interventions organized by the organization can be costly and can take longer to implement, managers are also encouraged to explore the opportunities they might have from their position to enhance employees' resources and reduce some of the demands (e.g., by on the one hand providing resources directly, and on the other hand by giving individuals the space to job craft towards the work conditions they find desirable). The obvious caveat here is that managers should also make sure that employees' performance and social relationships at work do not suffer from telecommuting. Indeed, when given the choice, employees may telecommute excessively, which would isolate them professionally (Gajendran \& Harrison, 2007). 


\section{Limitations and avenues for future research}

A first limitation of the current study is that the six month gap between the measurement of the telecommuting motives and the measurement of the outcomes may not be ideal. As evidenced, employees tend not to stay in the same telecommuting motive class for a very long time, so one could question if the effects of adopting a certain class will still be visible after a six month gap. Future research could therefore focus on how frequently employees switch classes and how long the effects of the classes last, for example, by conducting diary studies (Ohly et al., 2010).

A second limitation is that we did not have the data to test the influence of occupation or industry on telecommuting motives, although this has been suggested in variable-centred research (e.g., Mokhtarian et al., 1998). We did test for this influence indirectly, by focusing on the effects of job characteristics on telecommuting motives as well as on differences in motives between organizations, yet a more direct test would paint a more concrete and detailed picture of the prevalence of motive classes in different occupations and industries. This would, in our opinion, be a fruitful avenue for future research.

Third, the contextual correlates in this study exclusively come from the employee's work context (i.e., job demands and job resources). However, this is arguably only part of the story, as the non-work context also has the potential to exert influence over the motives to telecommute (e.g., when the employee's children are preparing for an exam, or when the employee's spouse lost his/her job; Salomon \& Ben-Akiva, 1983). Future research should therefore delve into how nonwork contextual variables correlate with the likelihood that an employee adopts a certain telecommuting motive class.

Also, in addition to the contextual correlates, individual characteristics might be of essence in shaping employee telecommuting motives. Even though we did not include individual differences, characteristics such as one's goal orientation (i.e., promotion or prevention focus), personality traits (e.g., extraversion, openness to experience or consciousness), or demographics, might be significant predictors of employee motives to telecommute. It is for instance, possible that individuals who have a lower need for social interactions and formulate their goals in terms of prevention of losses (rather than gains) will choose to telecommute more frequently as means of increasing their fit with the job. Also telecommuting motives might change throughout one's lifespan. While younger individuals who have to balance between their family (especially care for the children) and work responsibilities might choose to telecommute more frequently and mostly to aid a better worklife balance, older employees might choose to telecommute less often (to fulfill their social needs) and their choice for telecommuting might be mostly determined by the characteristics of the job (rather than by their home demands). Future contributions could therefore explore how personality characteristics shape employee motives and choice for frequency of telecommuting (for jobs where individuals can decide themselves how frequency can telecommute).

Whereas we established that employees might switch from one telecommuting category to another across six months, future studies incorporating multiple measurements over longer periods of time (e.g., 3 to 5 years) might shed more light on the different drives (e.g., personality and job characteristics) for and patterns of telecommuting. In the current study we found that employee telecommuting motives might change over six months depending on the changes in the characteristics of their job; yet it is possible that over a longer period of time more stable patterns emerge, due to individuals actively crafting their job to better fit their own personality and needs.

Finally, we would like to acknowledge two limitations of the questionnaire used in this study. To begin with, it included selfreported measures only, so a concern over common rater bias would be valid (although the two-wave design should have removed some of this bias; Podsakoff et al., 2003). Moreover, the questionnaire section on telecommuting motives featured only limited answering options (i.e., "yes" or "no"). With a more elaborate answering scale, more rigorous statistical analyses such as latent profile analysis would have been possible (B. O. Muthén \& Muthén, 2000). Such an analysis would paint an even more nuanced picture of how telecommuting motives tend to co-exist within an individual since it includes additional information about the relative strength of the motives.

\section{Conclusion}

The current study showed that employee telecommuting motives can be classified in three prominent telecommuting motive classes, i.e., the job requirement class, the efficiency class and the work-life balance class. A majority of employees tend to switch between these classes over the course of six months. Each of the classes has its own correlates, including job demands and job resources (especially speed of work and autonomy), and its own outcomes, with the job requirement class having the least positive outcomes and the work-life balance class having the most positive outcomes.

\section{Notes}

1 Arne Vanderstukken and Irina Nikolova share the first authorship as both authors strongly contributed to the development of the paper.

2 All participants had the opportunity to telecommute, so those who did not telecommute presumably also did not have a motive.

3 We also checked if the organization influenced the chance of belonging to a certain telecommuting motive class, but a Chi ${ }^{2}$ test revealed that the class distribution was similar across organizations (Pearson $\mathrm{Chi}^{2}(12)=17.60 ; \mathrm{p}=.13$ - the organizations SmallBusiness, SmallIT, MediumIT and BigEmp were omitted from this analysis because their small sample size resulted in expected cell counts smaller than 5).

\section{Disclosure statement}

No potential conflict of interest was reported by the author(s).

\section{Funding}

This work was supported by the Belspo [BR/143/A5/LITME@WORK].

\section{ORCID}

Irina Nikolova (iD) http://orcid.org/0000-0003-0908-0724 


\section{References}

Afonso, P., Fonseca, M., \& Teodoro, T. (2021). Evaluation of anxiety, depression and sleep quality in full-time teleworkers. Journal of Public Health (Oxford, England), Advance online publication, fdab164. https://doi.org/ 10.1093/pubmed/fdab164

Allen, T. D., Golden, T. D., \& Shockley, K. M. (2015). How effective is telecommuting? Assessing the status of our scientific findings. Psychological Science in the Public Interest, 16(2), 40-68. https://doi.org/10.1177/ 1529100615593273

Altieri, G., Della Ratta, F., \& Oteri, C. (2005). How to measure eWork in social surveys. In M. Ramioul, U. Huws, \& A. Bollen (Eds.), Measuring the Information Society (pp. 191-211). HIVA - KU Leuven.

Avgoustaki, A., \& Bessa, I. (2019). Examining the link between flexible working arrangement bundles and employee work effort. Human Resource Management, 58(4), 431-449. https://doi.org/10.1002/hrm.21969

Baert, S., Lippens, L., Moens, E., Sterkens, P., \& Weytjens, J. (2020). The COVID-19 crisis and telework: A research survey on experiences, expectations and hopes. IZA Discussion Paper No. 13229. Institute of Labor Economics. http://ftp.iza.org/dp13229.pdf

Bagley, M. N., \& Mokhtarian, P. L. (1997). Analyzing the preference for non-exclusive forms of telecommuting: Modeling and policy implications. Transportation, 24(3), 203-226. https://doi.org/10.1023/ A: 1004924601411

Bakker, A. B., \& Demerouti, E. (2007). The job demands-resources model: State of the art. Journal of Managerial Psychology, 22(3), 309-328. https:// doi.org/10.1108/02683940710733115

Bartholomew, K. J., Ntoumanis, N., Ryan, R. M., Bosch, J. A., \& ThøgersenNtoumani, C. (2011). Self-determination theory and diminished functioning: The role of interpersonal control and psychological need thwarting. Personality \& Social Psychology Bulletin, 37(11), 1459-1473. https://doi. org/10.1177/0146167211413125

Baruch, Y. (2000). Teleworking: Benefits and pitfalls as perceived by professionals and managers. New Technology, Work and Employment, 15(1), 34-49. https://doi.org/10.1111/1468-005X.00063

Baruch, Y., \& Nicholson, N. (1997). Home, sweet work: Requirements for effective home working. Journal of General Management, 23(2), 15-30. https://doi.org/10.1177/030630709702300202

Boudrias, V., Trepanier, S., Foucreault, A., Peterson, C., \& Frenet, C. (2020). Investigating the role of psychological need satisfaction as a moderator in the relationship between job demands and turnover intention among nurses. Employee Relations: The International Journal, 42(1), 213-231. https://doi.org/10.1108/ER-10-2018-0277

Cammann, C., Fichman, M., Jenkins, G. D., \& Klesh, J. (1983). Michigan Organizational Assessment Questionnaire. In S. E. Seashore, E. E. Lawler, P. H. Mirvis, \& C. Cammann (Eds.), Assessing organizational change: A guide to methods, measures and practices (pp. 71-138). WileyInterscience.

Charalampous, M., Grant, C. A., Tramontano, C., \& Michailidis, E. (2019). Systematically reviewing remote e-workers' well-being at work: A multidimensional approach. European Journal of Work and Organizational Psychology, 28(1), 51-73. https://doi.org/10.1080/ 1359432X.2018.1541886

Clark, S., \& Muthén, B. (2009). Relating latent class analysis results to variables not included in the analysis. https://www.statmodel.com/download/rela tinglca.pdf

Coenen, M., \& Kok, R. A. (2014). Workplace flexibility and new product development performance: The role of telework and flexible work schedules. European Management Journal, 32(4), 564-576. https://doi. org/10.1016/j.emj.2013.12.003

Como, R., Hambley, L., \& Domene, J. (2021). An exploration of work-life wellness and remote work during and beyond COVID-19. Canadian Journal of Career Development, 20(1), 46-56. Retrieved from: https:// cjcd-rcdc.ceric.ca/index.php/cjcd/article/view/92

Deci, E. L., \& Ryan, R. M. (2000). The "What" and "Why" of Goal Pursuits: Human Needs and the Self-Determination of Behavior. Psychological Inquiry, 11(4), 227-268. https://doi.org/10.1207/S15327965PLI1104_01

Delanoeije, J., \& Verbruggen, M. (2019). The use of work-home practices and work-home conflict: Examining the role of volition and perceived pressure in a multi-method study. Frontiers in Psychology, 10, 2362. https://doi.org/10.3389/fpsyg.2019.02362

Demerouti, E., Bakker, A. B., Nachreiner, F., \& Schaufeli, W. B. (2001). The job demands-resources model of burnout. Journal of Applied Psychology, 86 (3), 499-512. https://doi.org/10.1037/0021-9010.86.3.499

Dweck, C. S. (1986). Motivational processes affecting learning. American Psychologist, 41(10), 1040-1048. https://doi.org/10.1037/0003-066X.41. 10.1040

Eurostat. (2011). Population by type of disability, sex, age and labour status. Retrieved from Eurostat: https://appsso.eurostat.ec.europa.eu/nui/show. do?dataset=hlth_dlm040\&lang=en

Eurostat (2018). Disability statistics - poverty and income inequalities. Retrieved from Eurostat: https://ec.europa.eu/eurostat/statisticsexplained/index.php?title=Disability_statistics_-_poverty_and_income_ inequalities

Felstead, A., \& Henseke, G. (2017). Assessing the growth of remote working and its consequences for effort, well-being and work-life balance. New Technology, Work and Employment, 32(3), 195-212. https://doi.org/10. $1111 /$ ntwe.12097

Fernet, C., Austin, S., \& Vallerand, R. J. (2012). The effects of work motivation on employee exhaustion and commitment: An extension of the JD-R model. Work and Stress, 26(3), 213-229. https://doi.org/10.1080/ 02678373.2012 .713202

Gajendran, R. S., \& Harrison, D. A. (2007). The good, the bad, and the unknown about telecommuting: Meta-analysis of psychological mediators and individual consequences. Journal of Applied Psychology, 92(6), 1524-1541. https://doi.org/10.1037/0021-9010.92.6.1524

Geiser, C., Okun, M. A., \& Grano, C. (2014). Who is motivated to volunteer? A latent profile analysis linking volunteer motivation to frequency of volunteering. Psychological Test and Assessment Modeling, 56(1), 3-24. Retrieved from: https://core.ac.uk/download/pdf/25715984.pdf

Gostin, O. L., Friedman, E. A., \& Wetter, S. (2020). Responding to COVID-19: How to navigate a public health emergency legally and ethically. Hastings Center Report, 50(2), 1-5. https://doi.org/10.1002/hast.1090

Hajdu, G., \& Sik, E. (2018). Age, period, and cohort differences in work centrality and work values. Societies, 8(1), 11. https://doi.org/10.3390/soc8010011

Harris, L. (2003). Home-based teleworking and the employment relationship: Managerial challenges and dilemmas. Personnel Review, 32(4), 422-437. https://doi.org/10.1108/00483480310477515

Hartig, T., Kylin, C., \& Johansson, G. (2007). The telework tradeoff: Stress mitigation vs. constrained restoration. Applied Psychology, 56(2), 231-253. https://doi.org/10.1111/j.1464-0597.2006.00252.x

Hickman, A., \& Robison, J. (2020). Is working remotely effective? Gallup research says yes. Retrieved from Gallup: https://www.gallup.com/work place/283985/working-remotely-effective-gallup-research-says-yes.aspx

Hooper, D., Coughlan, J., \& Mullen, M. (2008). Evaluating model fit: A synthesis of the structural equation modelling literature. In 7 th European Conference on Research Methodology for Business and Management Studies (pp. 195-200), London.

International Labour Office (ILO). (2021). Working from home: From invisibility to decent work.

Jackson, P. J., \& van der Wielen, J. M. (1998). Teleworking: International Perspectives. Routledge.

Jemine, G., Dubois, C., \& Pichault, F. (2020). When the Gallic village strikes back: The politics behind 'new ways of working' projects. Journal of Change Management, 20(2), 146-170. https://doi.org/10.1080/ 14697017.2020.1720777

Kaduk, A., Genadek, K., Kelly, E. L., \& Moen, P. (2019). Involuntary vs. voluntary flexible work: Insights for scholars and stakeholders. Community, Work \& Family, 22(4), 412-442. https://doi.org/10.1080/ 13668803.2019.1616532

Keeney, J., Boyd, E. M., Sinha, R., Westring, A. F., \& Ryan, A. M. (2013). From "work-family" to "work-life": Broadening our conceptualization and measurement. Journal of Vocational Behavior, 82(3), 221-237. https:// doi.org/10.1016/j.jvb.2013.01.005

Kirves, K., Kinnunen, U., De Cuyper, N., \& Mäkikangas, A. (2014). Trajectories of perceived employability and their associations with well-being at work. Journal of Personnel Psychology, 13(1), 46-57. https://doi.org/10. 1027/1866-5888/a000103 
Lapierre, L. M., Van Steenbergen, E. F., Peeters, M. C., \& Kluwer, E. S. (2016). Juggling work and family responsibilities when involuntarily working more from home: A multiwave study of financial sales professionals. Journal of Organizational Behavior, 37(6), 804-822. https://doi.org/10. 1002/job.2075

Laursen, B., \& Hoff, E. (2006). Person-centered and variable-centered approaches to longitudinal data. Merrill-Palmer Quarterly: Journal of Developmental Psychology. Special Issue: Person-centered and Variablecentered Approaches to Longitudinal Data, 52(3), 377-389. Retrieved from: https://www.jstor.org/stable/23096200

Lautsch, B. A., Kossek, E. E., \& Eaton, S. C. (2009). Supervisory approaches and paradoxes in managing telecommuting implementation. Human Relations, 62(6), 795-827. https://doi.org/10.1177/0018726709104543

Linden, M. (2014). Telework research and practice: Impacts on people with disabilities. Work, 48(1), 65-67. https://doi.org/10.3233/WOR-141857

Lister, K. (2020). Work-at-home after Covid-19-Our forecast. Retrieved from GWA: https://globalworkplaceanalytics.com/work-at-home-after-covid -19-our-forecast

Magnusson, D. (2003). The person approach: Concepts, measurement models, and research strategy. In S. C. Peck \& R. W. Roeser (Eds.), New directions for Child and Adolescent development. Person-centered approaches to studying development in context (Vol. 101, pp. 3-23). Jossey-Bass.

Mäkikangas, A., Kinnunen, S., Rantanen, J., Mauno, S., Tolvanen, A., \& Bakker, A. B. (2014). Association between vigor and exhaustion during the workweek: A person-centered approach to daily assessments. Anxiety, Stress, and Coping, 27(5), 555-575. https://doi.org/10.1080/ 10615806.2013.860968

Martins, L. L., Gilson, L. L., \& Maynard, M. T. (2004). Virtual teams: What do we know and where do we go from here? Journal of Management, 30(6), 805-835. https://doi.org/10.1016/j.jm.2004.05.002

Maslach, C., Schaufeli, W. B., \& Leiter, M. P. (2001). Job burnout. Annual Review of Psychology, 52(1), 397-422. https://doi.org/10.1146/annurev. psych.52.1.397

McCutcheon, A. C. (1987). Latent class analysis. Sage.

Mellner, C., Aronsson, G., \& Kecklund, G. (2014). Boundary management preferences, boundary control, and work-life balance among full-time employed professionals in knowledge-intensive, flexible work. Nordic Journal of Working Life Studies, 4(4), 7-23. https://doi.org/10.19154/ njwls.v4i4.4705

Meyers, N., \& Hearn, G. N. (2001). Psychological factors and sustainable telecommuting: The importance of need for control. In Proceedings of the Seventh Americas Conference on Information systems (pp. 1908-1916), Boston. Association for Information Systems.

Mokhtarian, P. L., Bagley, M. N., \& Salomon, I. (1998). The impact of gender, occupation, and presence of children on telecommuting motivations and constraints. Journal of the American Society for Information Science, 49(12), 1115-1134. https://doi.org/10.1002/(SICI)1097-4571(1998) 49:12<1115::AID-ASI7>3.0.CO;2-Y

Mokhtarian, P. L., \& Salomon, I. (1994). Modeling the choice of telecommuting: Setting the context. Environment \& Planning A, 26(5), 749-766. https://doi.org/10.1068/a260749

Mokhtarian, P. L., \& Salomon, I. (1997). Modeling the desire to telecommute: The importance of attitudinal factors in behavioral models. Transportation Research Part A: Policy and Practice, 31(1), 35-50. https:// doi.org/10.1068/a260749

Muthén, B. O., \& Muthén, L. K. (2000). Integrating person-centered and variable-centered Analyses: Growth mixture modeling with latent trajectory classes. Alcoholism, Clinical and Experimental Research, 24(6), 882-891. https://doi.org/10.1111/j.1530-0277.2000.tb02070.x

Muthén, L. K., \& Muthén, B. O. (2019). Mplus. In The comprehensive modelling program for applied researchers: User's guide (pp. 5), Los Angeles, CA: Muthén \& Muthén.

Nielsen, K., Nielsen, M. B., Ogbonnaya, C., Känsälä, M., Saari, E., \& Isaksson, K. (2017). Workplace resources to improve both employee well-being and performance: A systematic review and meta-analysis. Work and Stress, 31 (2), 101-120. https://doi.org/10.1080/02678373.2017.1304463

Notelaers, G., De Witte, H., Van Veldhoven, M. J. P. M., \& Vermunt, J. K. (2007). Construction and validation of the short inventory to monitor psychosocial hazards. Médecine du Travail et Ergonomie, 44, 11-18. Retrieved from: https://www.academia.edu/164647/The_Construction
and_Validation_of_the_Short_Inventory_to_Monitor_Psychosocial_ Hazards_in_the_workplace

Nylund, K. L., Asparouhov, T., \& Muthén, B. O. (2007). Deciding on the number of classes in latent class analysis and growth mixture modeling: A Monte Carlo simulation study. Structural Equation Modeling: A Multidisciplinary Journal, 14(4), 535-569. https://doi.org/10.1080/ 10705510701575396

O'Neill, T. A., Hambley, L. A., Greidanus, N. S., MacDonnell, R., \& Kline, T. B. (2009). Predicting teleworker success: An exploration of personality, motivational, situational, and job characteristics. New Technology, Work \& Employment, 24(2), 144-162. https://doi.org/10.1111/j.1468-005X. 2009.00225.x

Ohly, S., \& Schmitt, A. (2015). What makes us enthusiastic, angry, feeling at rest or worried? Development and validation of an affective work events taxonomy using concept mapping methodology. Journal of Business and Psychology, 30(1), 15-35. https://doi.org/10.1007/s10869-013-9328-3

Ohly, S., Sonnentag, S., Niessen, C., \& Zapf, D. (2010). Diary studies in organizational research. Journal of Personnel Psychology, 9(2), 79-93. https://doi.org/10.1027/1866-5888/a000009

Onwezen, M. C., van Veldhoven, M. J. P. M., \& Biron, M. (2014). The role of psychological flexibility in the demands-exhaustion-performance relationship. European Journal of. European Journal of Work and Organizational Psychology, 23(2), 163-176. https://doi.org/10.1080/ $1359432 X .2012 .742242$

Parasuraman, S., \& Greenhaus, J. H. (2002). Toward reducing some critical gaps in work-family research. Human Resource Management Review, 12 (3), 299-312. https://doi.org/10.1016/S1053-4822(02)00062-1

Peters, P., Kraan, K., \& Echtelt, P. V. (2013). Floreren onder condities van Het Nieuwe Werken: Minder burn-out, meer toewijding? Tijdschrift Voor Arbeidsvraagstukken, 29(3), 304-321. https://doi.org/10.5117/2013.029. 003.304

Peters, P., Tijdens, K. G., \& Wetzels, C. (2004). Employees' opportunities, preferences, and practices in telecommuting adoption. Information \& Management, 41(4), 469-482. https://doi.org/10.1016/S0378-7206(03) 00085-5

Peters, P., Wetzels, C., \& Tijdens, K. (2008). Telework: Timesaving or time-consuming? An investigation into actual working hours. Journal of Interdisciplinary Economics, 19(4), 421-442. https://doi.org/10.1177/ 02601079X08001900407

Podsakoff, P. M., MacKenzie, S. B., Lee, J. Y., \& Podsakoff, N. P. (2003). Common method biases in behavioral research: A critical review of the literature and recommended remedies. Journal of Applied Psychology, 88 (5), 879-903. https://doi.org/10.1037/0021-9010.88.5.879

Pyöriä, P. (2011). Managing telework: Risks, fears and rules. Management Research Review, 34(4), 386-399. https://doi.org/10.1108/ 01409171111117843

Robèrt, M., \& Börjesson, M. (2006). Company incentives and tools for promoting telecommuting. Environment and Behavior, 38(4), 521-549. https://doi.org/10.1177/0013916505283422

Rocchi, M., Pelletier, L., Cheung, S., Baxter, D., \& Beaudry, S. (2017). Assessing need-supportive and need-thwarting interpersonal behaviours: The Interpersonal Behaviours Questionnaire (IBQ). Personality and Individual Differences, 104, 423-433. https://doi.org/10.1016/j.paid.2016.08.034

Salomon, I., \& Ben-Akiva, M. (1983). The use of the life-style concept in travel demand models. Environment \& Planning A, 15(5), 623-638. https://doi. org/10.1068/a150623

Schaufeli, W. B., \& Bakker, A. B. (2004). Bevlogenheid: Een begrip gemeten. Gedrag En Organisatie, 17(2), 89-112. https://doi.org/10.5117/2004.017. 002.002

Shockley, K. M., \& Allen, T. D. (2012). Motives for flexible work arrangement use. Community, Work \& Family, 15(2), 217-231. https://doi.org/10.1080/ 13668803.2011.609661

Sullivan, C., \& Lewis, S. (2001). Home-based telework, gender, and the synchronization of work and family: Perspectives of teleworkers and their Co-residents. Gender, Work, and Organization, 8(2), 123-145. https://doi.org/10.1111/1468-0432.00125

Van den Broeck, A., Lens, W., De Witte, H., \& Van Coillie, H. (2013). Unraveling the importance of the quantity and the quality of workers' motivation for well-being: A person-centered perspective. Journal of Vocational Behavior, 82(1), 69-78. https://doi.org/10.1016/j.jvb.2012.11.005 
Van den Broeck, A., Vansteenkiste, M., De Witte, H., \& Lens, W. (2008). Explaining the relationships between job characteristics, burnout, and engagement: The role of basic psychological need satisfaction. Work and Stress, 22(3), 277-294. https://doi.org/10.1080/02678370802393672

Van Sell, M., \& Jacobs, S. M. (1994). Telecommuting and quality of life: A review of the literature and a model for research. Telematics and Informatics, 11(2), 81-95. https://doi.org/10.1016/0736-5853(94)90033-7

Vandaele, K. (2005). A half century of trade union membership. The cyclical macro-determinants of postwar union growth in Belgium. World Political Science, 1(2), 53-72. Retrieved from: https://www.researchgate.net/pro file/Kurt-Vandaele/publication/250148017_A_Half_Century_of_Trade_ Union_Membership_The_Cyclical_Macro-Determinants_of_Postwar_ Union_Growth_in_Belgium/links/551166bd0cf29a3bb71dbb3c/A-HalfCentury-of-Trade-Union-Membership-The-Cyclical-MacroDeterminants-of-Postwar-Union-Growth-in-Belgium.pdf

Vander Elst, T., De Witte, H., \& De Cuyper, N. (2014). The Job Insecurity Scale: A psychometric evaluation across five European countries. European Journal of Work and Organizational Psychology, 23(3), 364-380. https:// doi.org/10.1080/1359432X.2012.745989

Vartiainen, M., Hakonen, M., Koivisto, S., Mannonen, P., Nieminen, M. P., Ruohomäki, V., \& Vartola, A. (2007). Distributed and mobile work. Places, people and technology. Otatieto.

Venkatesh, V., \& Johnson, P. (2002). Telecommuting technology implementations: A within-and between-subjects longitudinal field study. Personnel Psychology, 55(3), 661-687. https://doi.org/10.1111/j.17446570.2002.tb00125.x

Venkatesh, V., \& Speier, C. (1999). Computer technology training in the workplace: A longitudinal investigation of the effect of mood.
Organizational Behavior and Human Decision Processes, 79(1), 1-28. https://doi.org/10.1006/obhd.1999.2837

Venkatesh, V., \& Speier, C. (2000). Creating an effective training environment for enhancing telework. International Journal of Human-Computer Studies, 52(6), 991-1005. https://doi.org/10.1006/ijhc.1999.0367

Vermunt, J. K., \& Magidson, J. (2002). Latent class cluster analysis. In J. A. Hagenaars \& A. L. McCutcheon (Eds.), Applied latent class analysis (pp. 89-106). Cambridge University Press.

Walls, M., Safirova, E., \& Jiang, Y. (2007). What drives telecommuting? Relative impact of worker demographics, employer characteristics, and job types. Transportation Research Record: Journal of the Transportation Research Board, 2010(1), 111-120. https://doi.org/10. 3141/2010-13

Welz, C., \& Wolf, F. (2010). Telework in the European Union. Dublin: European Foundation for the Improvement of Living and Working Conditions (Eurofound). Retrieved from : https://www.eurofound.europa.eu/publica tions/report/2010/telework-in-the-european-union

Wessels, C., Schippers, M. C., Stegmann, S., Bakker, A. B., van Baalen, P. J., \& Proper, K. I. (2019). Fostering flexibility in the new world of work: A model of time-spatial job crafting. Frontiers in Psychology, 10,505. https://doi.org/10.3389/fpsyg.2019.00505

Wicks, D. (2002). Successfully increasing technological control through minimizing workplace resistance: Understanding the willingness to telework. Management Decision, 40(7), 672-681. https://doi.org/10. 1108/00251740210438508

Wrzesniewski, A., \& Dutton, J. E. (2001). Crafting a job: Revisioning employees as active crafters of their work. Academy of Management Review, 26 (2), 179-201. https://doi.org/10.5465/amr.2001.4378011 